\title{
The British government's Troubled Families Programme
}

\author{
A flawed response to riots and youth offending
}

\author{
Adam Fletcher lecturer in sociology and social policy ${ }^{1}$, Frances Gardner professor of child and \\ family psychology ${ }^{2}$, Martin McKee professor of European public health ${ }^{1}$, Chris Bonell professor of \\ sociology and social intervention ${ }^{2}$
}

${ }^{1}$ Faculty of Public Health and Policy, London School of Hygiene and Tropical Medicine, London WC1H 9SH, UK; ${ }^{2} \mathrm{Centre}$ for Evidence Based Intervention, Department of Social Policy and Intervention, University of Oxford, OX1 2ER, UK

The British government has recently established the Troubled Families Programme in response to the riots in England in 2011, scaling up a non-negotiable version of the previous government's Family Intervention Projects. Their aim is to prevent further riots. Key workers will assess the needs of families identified as being troubled and coordinate a year long programme of intensive family support to tackle antisocial behaviour, misuse of drugs and alcohol, and youth crime. However, evidence for the effectiveness of family intervention projects is weak, being made up of small scale evaluations without external comparison groups. ${ }^{1}$ A systematic review commissioned by the previous government found no studies to support the claim that such interventions improve outcomes for families. $^{2}$

Even if the programme were effective for those receiving it, targeting $120<$ thin>000 families, which represent less than $2 \%$ of all families in England, would miss most future rioters and young offenders. Public health scientists know that disease prevention approaches aimed only at people identified as at high risk of most non-communicable diseases are unlikely to have much effect at the population level when risk follows a bell shaped curve, because in such cases most disease arises from those at low to medium risk. This seems also to be true for youth offenders. In London, the "worst" 5\% of families account for only around a quarter of all offenders, with a similar pattern emerging in other countries, such as the United States. ${ }^{3}$

The programme may also inadvertently cause harms. Targeted interventions can sometimes cause harm because labelling individuals can exacerbate risky behaviours. The compulsory nature of the programme could make it particularly liable to bring about such harms. Some activities within the programme will bring together troubled families and young people, and some studies have suggested this can also amplify risky behaviour. $^{4}$
A historical example of a somewhat similar intervention illustrates the potential for well intended targeted interventions to cause harm. The Cambridge-Somerville project targeted preadolescent boys in low income neighbourhoods in Massachusetts in the 1940s. ${ }^{45}$ The intervention involved regular home visits by support workers to mentor youth, deal with family needs, and coordinate services, and boys in the intervention were encouraged to participate in community groups, sports, and summer camps. When followed up 30 years later, those who had received the intervention had higher rates of mortality, alcohol dependence, serious mental illness, and criminal convictions than those in the comparison group. Moreover, adverse effects seemed to result from intervention components that aggregated at risk boys into group activities. Caution is clearly needed when applying evidence from an intervention that, although somewhat similar, was undertaken in the US more than 50 years ago. However, the long term outcomes of the Cambridge-Somerville project show the potential for an intervention like the Troubled Families Programme to cause harms. Weak evaluations of the Family Intervention Project cannot rule out the possibility of similar outcomes.

What would a more adequate response involve? If the government wants to foster healthy parenting skills and prevent youth problem behaviours, a substantial UK and international evidence base suggests this should involve effective parenting programmes that target 3-8 year olds. ${ }^{6}$ These interventions can be delivered to families in need (not only those deemed to be troubled) within community based settings, such as children's centres. ${ }^{7}$ Evidence suggests that functional family therapy and multisystemic therapy are effective at reducing youth offending, ${ }^{8}$ including in UK settings.

However, even these evidence based interventions may not be able to reach all in need and may be insufficient to achieve substantial effects at the population level'; they should therefore 
be complemented with universal interventions. Good evidence exists for a variety of universal school based interventions to challenge disengagement and underachievement, such as changing how teachers interact with students and enhancing social and emotional learning. ${ }^{10}{ }^{11}$ However, the extent to which these interventions might be feasible and effective in England is likely to be undermined by recent changes in education policy. Ofsted, the schools inspectorate, is no longer required to assess schools on the extent to which they promote student wellbeing, and the previous National Healthy Schools Programme has been abandoned. Furthermore, there is evidence that a strong focus on high stakes tests and league tables may reduce the attention that schools give to the most disadvantaged students and exacerbate educational inequalities. ${ }^{12}$

The Troubled Families Programme may be an eye catching populist response to the riots, but obliging troubled families to accept a non-negotiable non-evidence-based intervention is unlikely to prevent future disorder and may well produce unintended harms. Policy makers should focus instead on a combination of evidence based targeted and universal interventions and ensure that the broader policy environment supports these.

Competing interests: All authors have completed the ICMJE uniform disclosure form at www.icmje.org/coi_disclosure.pdf (available on request from the corresponding author) and declare: no support from any organisation for the submitted work; no financial relationships with any organisations that might have an interest in the submitted work in the previous three years; no other relationships or activities that could appear to have influenced the submitted work.
Provenance and peer review: Not commissioned; externally peer reviewed.

1 Lloyd D, Wollny I, White C, Gowland S, Purdon S. Monitoring and evaluation of family intervention services and projects between February 2007 and March 2011. Department for Education, 2011. https://www.education.gov.uk/publications/RSG/AllPublications/ Page1/DFE-RR174.

2 Newman M, Bangpan M, Brunton J, Tripney J, Williams T, Thieba A, et al. Interventions to improve the co-ordination of service delivery for high cost high harm household units. A systematic rapid evidence assessment. EPPI Centre, 2007. http://eprints.ioe.ac.uk/ 5766/2/Newman2007InterventionsReport.pdf.

3 Farrington DP, Jolliffe D, Loeber R, Stouthamer-Loeber M, Kalb LM. The concentration of offenders in families, and family criminality in the prediction of boys' delinquency. $J$ Adolesc 2001;24:579-96.

4 Dishion TJ, McCord J. When interventions harm: peer groups and problem behaviours. Am Psychol 1999:54:755-64.

5 McCord J. A thirty-year follow-up of treatment effects. Am Psychol 1978;33:284-9.

6 Piquero AR, Farrington DP, Welsh BC, Tremblay RE, Jennings W. Effects of early family/ parent training programmes on antisocial behaviour and delinquency. Campbell Systematic Reviews 2008:11.

7 Hutchings J, Bywater T, Daley D, Gardner F, Whitaker C, Jones K, et al. Parenting intervention in Sure Start services for children at risk of developing conduct disorder: pragmatic randomised controlled trial. BMJ 2007;334:678-85.

8 Woolfenden S, Williams KJ, Peat J. Family and parenting interventions in children and adolescents with conduct disorder and delinquency aged 10-17. Cochrane Database Syst Rev 2001;2:CD003015.

9 Dodge K. Community intervention and public policy and the prevention of antisocial behaviour. J Child Psychol Psychiatry 2009;50:194-200.

10 Allen JP, Pianta RC, Gregory A, Mikami A, Lun J. An interaction-based approach to enhancing secondary school instruction and student achievement. Science 2011;333:1034-7.

11 Durlak JA, Weissberg RP, Dymnicki AB, Taylor RD, Schellinger KB. The impact of enhancing students' social and emotional learning: a meta-analysis of school-based universal interventions. Child Dev 2011:82:405-32.

12 Bonell C, Fletcher A, McKee M, Sorhaindo A, Wells H. How market-oriented education policies might influence young people's health: development of a logic-model from qualitative case-studies in English secondary-schools. J Epidemiol Community Health 2011; published online 28 June.

Cite this as: BMJ 2012:344:e3403

(c) BMJ Publishing Group Ltd 2012 